\title{
Evidence for Opening of Hair-Cell Transducer Channels after Tip-Link Loss
}

\author{
Jens Meyer, ${ }^{1}$ David N. Furness, ${ }^{2}$ Hans-Peter Zenner, ${ }^{1}$ Carole M. Hackney, ${ }^{2}$ and Anthony W. Gummer ${ }^{1}$ \\ ${ }^{1}$ Department of Otolaryngology, Section of Physiological Acoustics and Communication, University of Tübingen, 72076 \\ Tübingen, Germany, and 2Department of Communication and Neuroscience, Keele University, \\ Keele, Staffordshire ST5 5BG, United Kingdom
}

The mechanosensitive transducer channels of hair cells have long been proposed to be gated directly by tension in the tip links. These are thin, elastic extracellular elements connecting the tips of adjacent stereocilia located on the apical surface of the cell. If this hypothesis is true, the channels should close after destruction of tip links. The hypothesis was tested pharmacologically using receptor currents obtained in response to mechanical stimulation of the stereociliary bundle of outer hair cells isolated from the adult guinea pig cochlea. Application of elastase $(20 \mathrm{U} / \mathrm{ml})$ or 1,2-bis(2-aminophenoxy)ethane- $N, N, N^{\prime}, N^{\prime}$ tetra-acetic acid (BAPTA; $5 \mathrm{~mm}$ ), both of which are known to disrupt tip links in other hair-cell preparations, led to the expected irreversible loss of receptor currents. However, the cells then displayed a maintained inward current, implying that channels were left permanently open. This current was similar in magnitude to the receptor current before treatment and was reduced reversibly by known blockers of mechanosensitive channels, namely, dihydrostreptomycin (100 $\mu \mathrm{M})$, amiloride (300 $\mu \mathrm{M})$, and gadolinium ions ( $1 \mathrm{~mm})$. These observations suggest that the maintained current flows through the mechanosensitive channels. Electron microscopical analysis of isolated hair cells, exposed to the same concentrations of elastase or BAPTA as in the electrophysiological experiments, demonstrated an almost total loss of tip links in hair bundles that showed no evidence of other mechanical damage. It is concluded that although the tip links are required for mechanoelectrical transduction, the channels are not gated directly by the tip links.

Key words: mechanoelectrical transduction; outer hair cells; tip link; elastase; low calcium; channel gating; tip-link hypothesis; BAPTA
The hair bundle is the mechanosensitive apparatus of hair cells responsible for sensory transduction in auditory, vestibular, and lateral-line systems (Hudspeth and Jacobs, 1979). In mammals, each hair bundle consists of stereocilia arranged in rows of different lengths, which are connected by fine extracellular filaments (Pickles et al., 1984) called "tip links" that run between the tips of the shorter stereocilia and the sides of the taller ones in the next row. Channels open when the bundle is deflected in the direction of the tallest stereocilium. It has been estimated that each stereocilium possesses only one to five mechanosensitive transducer channels (Howard et al., 1988). A range of physiological experiments, including extracellular focal recording around the hair bundle (Hudspeth, 1982) and calcium imaging (Denk et al., 1995; Lumpkin and Hudspeth, 1995), have suggested that these channels are likely to be located within $2-3 \mu \mathrm{m}$ of the tips of the stereocilia. The directional sensitivity of the receptor current to mechanical stimulation is consistent with (1) the axis of bilateral symmetry of the hair bundle (Shotwell et al., 1981), (2) elastic expansion of tip links (Howard et al., 1988), and (3) only one tip link connecting adjacent stereocilia. It has been proposed that the tip links gate the channels like springs and that they are more or less directly connected to the mechanosensitive ion channels (Pickles et al., 1984). Direct mechanical gating is sup-

Received June 5, 1998; accepted June 22, 1998.

This work was supported by the Deutsche Forschungsgemeinschaft, Klinische Forschergruppe "Hörforschung," Projekt A and the Wellcome Trust. We thank V. Lesiuk for technical assistance.

Correspondence should be addressed to Dr. Jens Meyer, University of Tübingen, Department of Otolaryngology, Section of Physiological Acoustics and Communication, Silcherstrasse 5, 72076 Tübingen, Germany.

Copyright (C) 1998 Society for Neuroscience $\quad 0270-6474 / 98 / 186748-09 \$ 05.00 / 0$ ported by the fact that the channels open with a delay of $\sim 40 \mu \mathrm{sec}$ after the mechanical stimulus, which is much too fast to involve second messenger systems (Corey and Hudspeth, 1979).

In the resting position, the transducer channels are not totally closed but are reported to have an open probability of $\sim 10-20 \%$ attributable to the normal resting tension of the gating springs (Corey and Hudspeth, 1983). If the tip links are the gating springs, then their destruction should lead to loss of this resting tension and consequently to closure of the transducer channels. Tip links have been shown to be sensitive to elastase in glutaraldehyde-fixed mammalian organ of Corti (Osborne and Comis, 1990). Elastase treatment of isolated guinea pig outer hair cells (OHCs) led to an irreversible loss of mechanoelectrical transduction (Preyer et al., 1995), suggesting that the tip links are indeed essential elements of the transduction apparatus.

However, there is only indirect evidence of the tip-link hypothesis. Recently, a region directly below the tip-link region was described in which the cell membranes of adjacent stereocilia come into close contact (Hackney and Furness, 1995). Positive staining with antibodies against the amiloride-binding site of an epithelial sodium channel led those authors to propose that the transducer channels might be located in this position, which they called the "contact region." To date, the results of electrophysiological experiments do not contradict a possible localization of the channel in this region. Because of the small distance between the tip link and the contact region $(\sim 100 \mathrm{~nm})$, it is extremely difficult to discriminate between these two locations, even with high-resolution calcium-imaging methods (Denk et al., 1995). The experiments presented in this paper provide the first electrophysiological evidence that the transducer channels are not directly 
connected to the tip links. They are in fact more consistent with a more indirect connection between the links and the channels or with a localization in the contact region.

Parts of this work have been presented at the $21^{\text {st }}$ AROMidwinter Research Meeting, St. Petersburg Beach, Fl, February 1998.

\section{MATERIALS AND METHODS}

Cell isolation. OHCs were mechanically isolated from all turns of the adult guinea pig cochlea, with most cells derived from the apical one-half of the cochlea. The procedure is described in detail elsewhere (Preyer et al., 1996). After separation, the cells were allowed to adhere to a poly-L-lysine- (0.1\%; Sigma, Deisenhofen, Germany) coated coverslip in a droplet $(200 \mu \mathrm{l})$ of HBSS $(300 \mathrm{mOsm} / \mathrm{l}$; pH 7.25; Seromed, Berlin, Germany) at room temperature $\left(20-22^{\circ} \mathrm{C}\right)$. The extracellular $\mathrm{Ca}^{2+}$ concentration in these experiments was $1.25 \mathrm{~mm}$. For experiments in which gadolinium ions were applied to the stereociliary bundle, a phosphatefree extracellular solution was used (in $\mathrm{mm}, 135 \mathrm{NaCl}, 5.4 \mathrm{KCl}, 1.25$ $\mathrm{CaCl}_{2}, 1 \mathrm{MgCl}_{2}, 10 \mathrm{HEPES}$, and $300 \mathrm{mOsm} / 1, \mathrm{pH}$ 7.25). All experiments were conducted under continuous video control (Hamamatsu 2400) using an inverted microscope (Labovert; Leitz, Wetzlar, Germany); total magnification was $800 \times$.

Whole-cell recording. Electrophysiological recordings were made in current or voltage clamp at a holding potential of $-60 \mathrm{mV}$, using an EPC-7 patch-clamp amplifier (List-Electronic, Darmrstadt, Germany). Soda glass pipettes filled with $\mathrm{K}^{+}$solution (in $\mathrm{mm}, 140 \mathrm{KCl}, 2 \mathrm{MgCl}_{2}, 11$ EGTA, $0.1 \mathrm{CaCl}_{2}$, and $10 \mathrm{HEPES}$ ) were used for whole-cell patch-clamp recordings (Hamill et al., 1981). The electrode resistance in extracellular fluid was $2-5 \mathrm{M} \Omega$. Only cells with a resting potential less than $-50 \mathrm{mV}$ and intact hair bundles, as assessed by light microscopy, were used. In some experiments, $\mathrm{KCl}$ was replaced by $140 \mathrm{~mm} \mathrm{CsCl}$ to block most of the basolateral channels.

Drug application. Unless otherwise stated, all chemicals used were obtained from Sigma. Drugs were pressure-applied (Eppendorf 5242) locally to the hair-bundle region from a distance of $\sim 10 \mu \mathrm{m}$, using double-barreled glass capillaries with a tip diameter of $\sim 5 \mu \mathrm{m}$. Care was taken not to elicit stereocilia movement during drug application. With a double photodiode system (BPX48; Siemens AG, Erlangen, Germany) mounted on the microscope, it was possible to ensure that there were no mechanical artifacts attributable to pressure application of the drugs. The aminoglycoside dihydrostreptomycin (DHSM; $100 \mu \mathrm{M}$ ) (Kroese et al., 1989; Kimitsuki and Ohmori, 1993), amiloride (300 $\mu \mathrm{M})$ (Rüsch et al., 1994), or gadolinium ions (1 mM) (Kimitsuki et al., 1996) were used to test for transduction channels. For destruction of tip links, either the enzyme elastase $(20 \mathrm{U} / \mathrm{ml})$ (Osborne and Comis, 1990) or 1,2-bis(2aminophenoxy)ethane- $N, N, N^{\prime}, N^{\prime}$-tetra-acetic acid (BAPTA; $5 \mathrm{~mm}$; for lowering the $\mathrm{Ca}^{2+}$ concentration) (Assad et al., 1991) was used. For blocking purinoreceptors located in the stereocilia (Mockett et al., 1994), suramin (300 $\mu \mathrm{M}$; Bayer, Wuppertal, Germany) was applied to the hair bundle.

Mechanically induced hair-bundle movement. A fluid jet composed of extracellular solution (HBSS) and driven by a piezoelectric crystal was used to deflect the hair bundle (Saunders and Szymko, 1989). The tip of the micropipette, which served as a nozzle for the fluid jet, had a diameter of $5-8 \mu \mathrm{m}$ and was placed at a distance of $\sim 10 \mu \mathrm{m}$ from the hair bundle. The piezoelectric crystal was driven sinusoidally with a frequency of $8 \mathrm{~Hz}$ (Hewlett-Packard 8904A multifunction synthesizer). The stimulus amplitude was set to produce saturated receptor currents. Data were stored on DAT tape or were analog-to-digital-converted by a 14-bit PCM processor and stored on hard disk for later analysis by appropriate software (TIDA, Batelle, Germany).

Scanning electron microscopy. The effects of elastase and BAPTA application on hair-bundle morphology were assessed in isolated hair cells. A total of six guinea pigs were used, and the cochleae were partitioned between treatments as follows: BAPTA $(n=4)$, elastase $(n=$ $4)$, and HBSS alone $(n=4)$. The cells were isolated onto coverslips, using the same preparation techniques described for electrophysiological recordings. Cells were incubated in either $5 \mathrm{~mm}$ BAPTA in HBSS for 10 $\min (n=2)$ or $10 \mathrm{sec}(n=2), 20 \mathrm{U} / \mathrm{ml}$ elastase for $10 \mathrm{~min}$, or HBSS for $10 \mathrm{~min}$. The coverslips were then carefully washed with HBSS and flooded with $2.5 \%$ glutaraldehyde in $0.1 \mathrm{M}$ sodium cacodylate buffer containing $2 \mathrm{mM} \mathrm{CaCl}_{2}$. After $1 \mathrm{hr}$ in this fixative, they were post-fixed with $1 \% \mathrm{OsO}_{4}$ in the same buffer for $1 \mathrm{hr}$, washed thoroughly, and then incubated alternately in saturated aqueous sodium thiocarbohydrazide solution for $20 \mathrm{~min}$ and $1 \% \mathrm{OsO}_{4}$ in buffer twice more, with washing between each step. The preparations were then dehydrated in 70,90 , and two dry $100 \%$ ethanol steps (10 min each) before critical-point drying from liquid $\mathrm{CO}_{2}$, attached to stubs using sticky carbon pads, and examined in a field-emission scanning electron microscope (Hitachi S-4500) at $2-3 \mathrm{kV}$. All isolated cells with intact hair bundles at appropriate orientations were examined, the number of possible tip-link sites were counted, and each site was assigned to one of three categories: (1) "obscured" (in which the tip of the stereocilium was covered by material and no assessment could be made), (2) "fused" (in which the stereocilium was fused to a neighbor in a way that precluded the presence of a link), and (3) "visible" (in which the region between two stereocilia was sufficiently visible to make a decision about the state of the tip links). If classified as visible, a site was assigned to one of five categories: (1) "intact" (tip links present), (2) "broken" (tip links severed), (3) "remnant" (stump of a tip link evident on the membrane of a stereocilium), (4) "absent" (no evidence of any tip-link material), and (5) "uncertain" (some evidence of a link present but not capable of being readily categorized). In some cases, small portions of the organ of Corti containing several cells were left intact; in these cases, a small number of randomly selected bundles was included in the assessment.

\section{RESULTS}

\section{Block of transducer channels by dihydrostreptomycin}

Aminoglycosides, such as DHSM, cause a voltage-dependent block of mechanoelectrical transduction channels (Kroese et al., 1989; Kimitsuki and Ohmori, 1993). In the present series of experiments, DHSM was used as a control for the presence of open mechanoelectrical transducer channels. The series of experiments in this section describe the effect of DHSM on mechanoelectrical transducer channels of untreated OHCs.

Figure 1 shows the effect of DHSM $(100 \mu \mathrm{M})$ on the receptor current of an isolated hair cell; sinusoidal deflection of the hair bundle with an amplitude of $\sim 180 \mathrm{~nm}$ leads to a saturated receptor current of $\sim 45 \mathrm{pA}$ (Fig. 1a). Application of DHSM produces a reduction of the receptor current (Fig. 1b). The receptor current fully recovers after terminating the application and washing out the drug.

That DHSM actually blocks mechanoelectrical transducer channels in our experimental conditions was examined by application of DHSM during static deflection of the intact hair bundle, either in the direction of the tallest row of stereocilia (positive deflection) or in the opposite direction (negative deflection). Static deflection of $\sim 250 \mathrm{~nm}$ in the positive direction resulted in a maintained, saturated inward current, whereas static deflection of the same amplitude in the negative direction resulted in a maintained zero current (Fig. 2). That is, these static deflections caused the transducer channels to be permanently opened or closed. Under these conditions, DHSM had no effect during static deflection in the negative direction but caused reversible reduction of the receptor current during static deflection in the positive direction. This experiment indicates that the reduction of receptor current by DHSM is indeed caused by blocking the mechanoelectrical transducer channels.

\section{Abolition of transduction by elastase}

If the tip links are indeed connected directly to the transducer channels, then their destruction by elastase should cause similar effects to those caused by channel block with DHSM. Therefore, the responses of cells $(n=6)$ to application of DHSM $(100 \mu \mathrm{M})$ followed by elastase treatment $(20 \mathrm{U} / \mathrm{ml})$ were examined. No obvious change of shape of the hair bundle because of elastase treatment (such as splaying of the stereocilia) was seen by light microscopy. Exposure to DHSM during mechanical stimulation (Fig. 3a) led to reversible loss of the receptor current (Fig. 3b), similar to that for the cell illustrated in Figure $1 b$. Then, elastase 


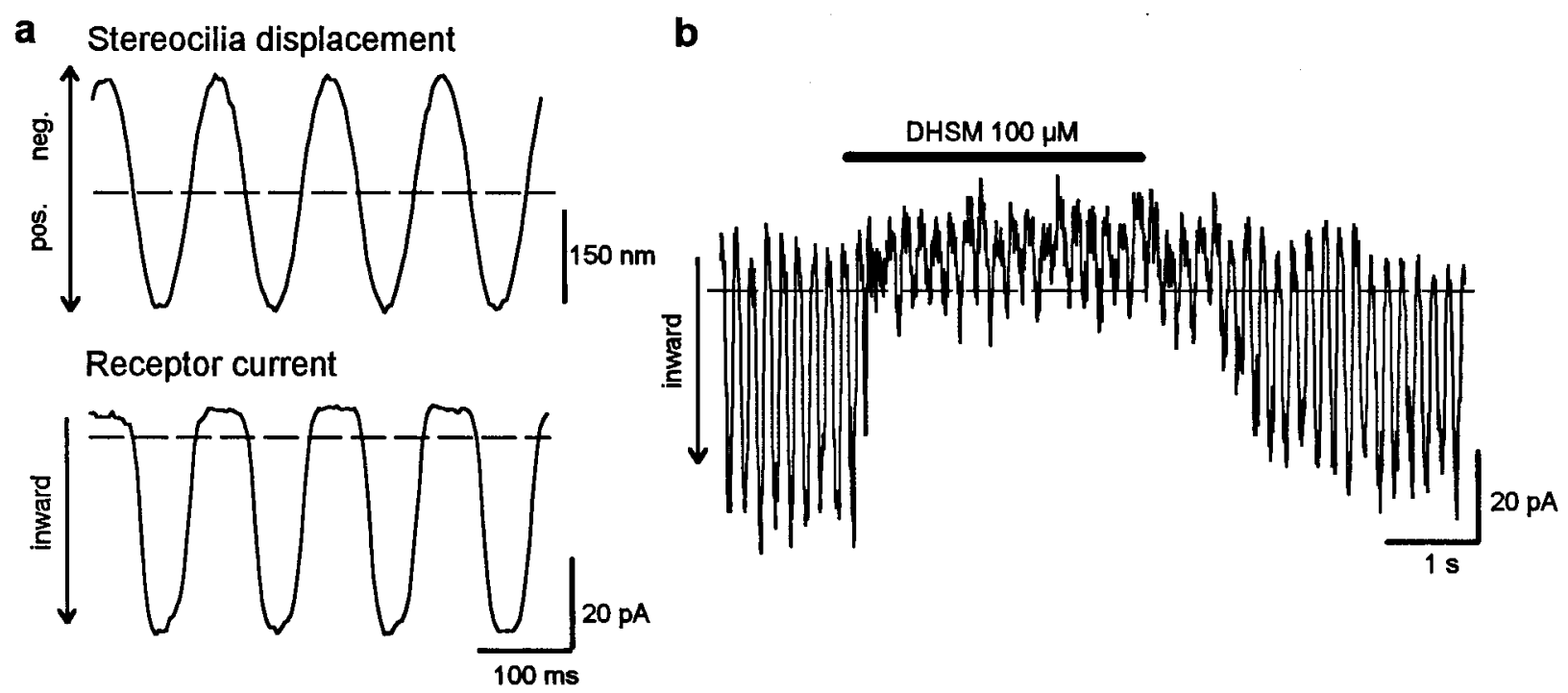

Figure 1. Effect of DHSM on the receptor current of an isolated outer hair cell. $a$, Sinusoidal mechanical stimulation of the hair bundle with an amplitude of $180 \mathrm{~nm}$ (top) leads to a saturated receptor response of $45 \mathrm{pA}$ peak-to-peak (bottom). The holding potential is $-60 \mathrm{mV}$. $b$, Application of $100 \mu \mathrm{M}$ DHSM leads to reversible loss of the receptor current. The dashed lines in this and the following figures represent the resting current without mechanical stimulation. Inward currents are directed downward.

\section{Stereocilia displacement}

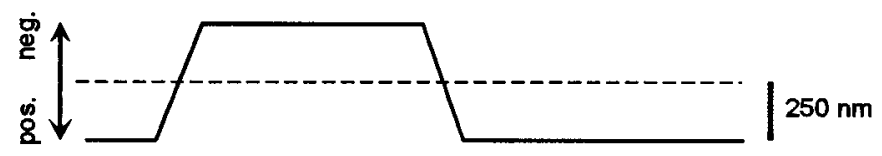

Receptor current

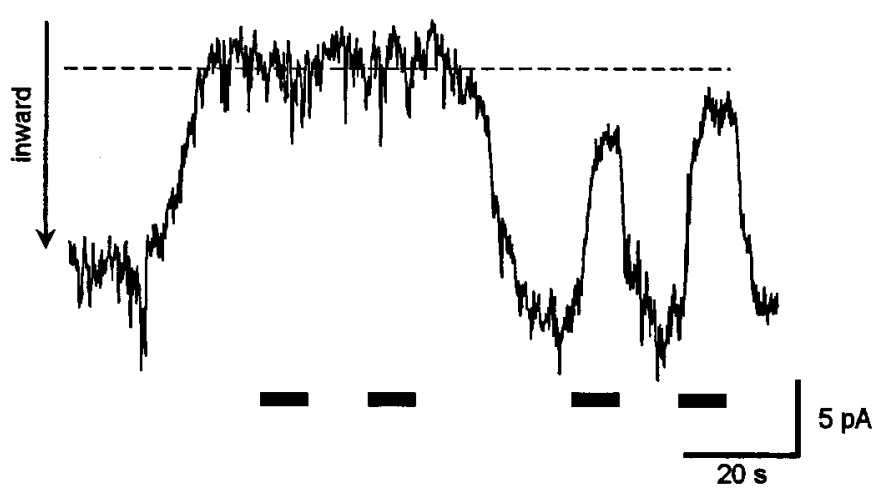

Figure 2. DHSM blocks only the mechanoelectrical transducer channels of the outer hair cell. To examine whether it is really the transducer channel that is blocked by DHSM $(100 \mu \mathrm{M})$, we statically deflected the hair bundle by $\sim 250 \mathrm{~nm}$ in the positive or negative direction (top), so that all transducer channels were either open or closed, respectively (bottom). The receptor current is unaltered by the presence of DHSM during static negative deflection, whereas it is reduced by DHSM during static positive deflection. This indicates that under these experimental conditions, DHSM blocks only the mechanoelectrical transducer channels. Horizontal bars indicate application of $100 \mu \mathrm{M}$ DHSM.

was applied after recovery $(25 \mathrm{sec})$ of the receptor current from the DHSM treatment (Fig. 3c). Elastase caused an irreversible loss of the phasic component of the receptor current $(8 \mathrm{~Hz})$. But in contrast to DHSM, the current was not totally abolished.
Instead, a sustained inward current was recorded (tonic current) with similar amplitude (50 pA) to the peak-to-peak value of the receptor (phasic) current before elastase treatment. This tonic component persisted in the absence of stereocilia deflection. The amplitude and tonic form of this stimulus-independent, inward current suggest that transducer channels are in a permanently opened state after loss of tip links.

Evidence that the sustained current after elastase treatment originated from permanently opened transducer channels was obtained by applying $100 \mu \mathrm{M}$ DHSM after previous elastase treatment (in a different set of cells). Cells did not react to sinusoidal mechanical stimulation $(8 \mathrm{~Hz})$ after elastase treatment. However, a total and reversible block of the sustained inward current was caused by application of DHSM (Fig. $3 d$ ). The amplitude of this suppressed current was similar to the amplitude of the receptor current before elastase treatment. This effect is summarized in Figure $3 e$ for different cells $(n=6)$. A strong positive correlation is seen between the amplitude of the DHSMsuppressed tonic current and the amplitude of the receptor current before elastase treatment. This strongly suggests that the sustained current flows through permanently opened transducer channels.

Aminoglycosides such as DHSM are also known to affect other channels, such as $\mathrm{P}_{2 \mathrm{X}}$ receptors in the stereocilia (Lin et al., 1993). Binding of extracellular ATP to the $\mathrm{P}_{2 \mathrm{X}}$ receptors leads to the opening of a cation channel and to a strong inward current (Nakagawa et al., 1990) and $\mathrm{Ca}^{2+}$ influx (Ashmore and Ohmori, 1990). To exclude the possibility that DHSM blocked $P_{2 x}$ receptors, we performed a second series of experiments ( $n=3$ cells). After treatment with elastase, a potent $\mathrm{P}_{2 \mathrm{x}}$-receptor blocker, suramin $(250 \mu \mathrm{M})$, was applied to the hair bundle. Whereas DHSM led to block of the elastase-induced tonic current, suramin had no detectable effect (data not shown). This indicates that $\mathrm{P}_{2 \mathrm{X}}$ receptors are not activated in the experiments with elastase. In another series of experiments (Meyer et al., 1997), application of ATP $(300 \mu \mathrm{M})$ to an intact hair bundle was found to produce a large inward current of several hundred picoamperes, much larger than the transduction current. The ATP-induced inward current 
a

Driving voltage $(8 \mathrm{~Hz})$

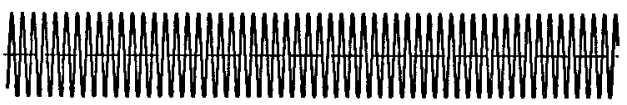

\begin{tabular}{l} 
b Receptor current \\
DHSM $100 \mu \mathrm{M}$ \\
\hline
\end{tabular} d Current after elastase-treatment

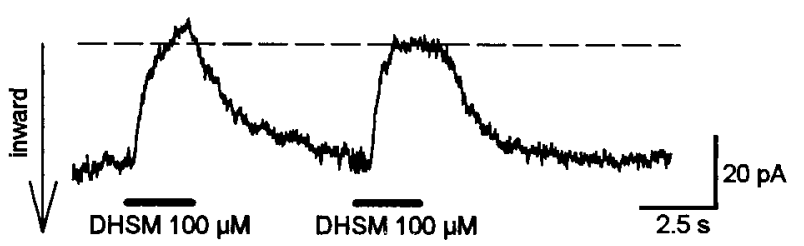

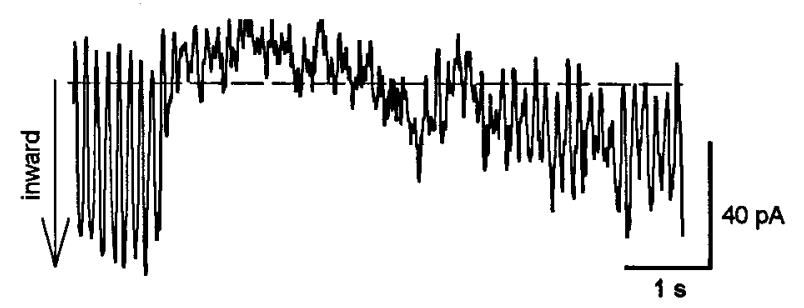

C Receptor current
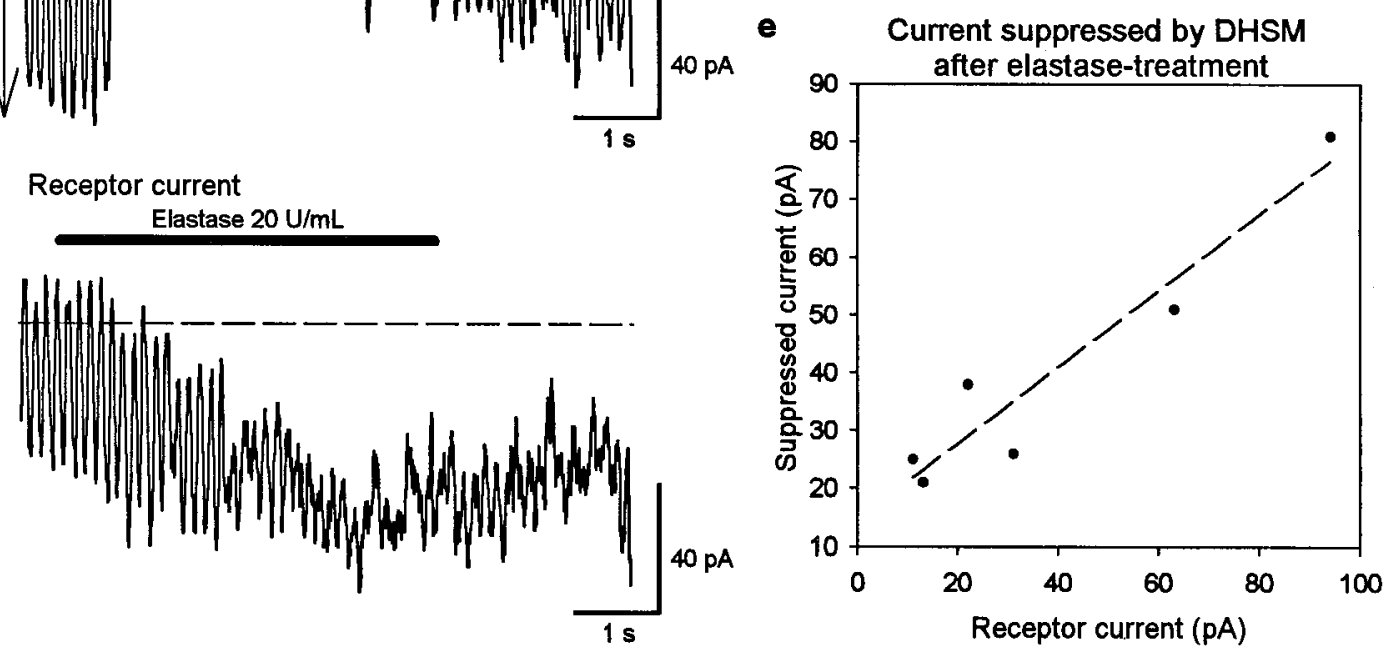

Figure 3. Elastase and DHSM have different effects on mechanoelectrical transduction. $a-c$, Whereas $100 \mu \mathrm{M}$ DHSM causes reversible loss of the receptor current $(b)$, subsequent application $(25 \mathrm{sec}$ later $)$ of elastase $(20 \mathrm{U} / \mathrm{ml})$ to the same cell causes an irreversible loss of the phasic component of the current but a steady (tonic) inward current $(c)$, which persisted in the absence of stereocilia deflection. $d$, The current flow after previous elastase treatment (in a cell different from that in $b$ and $c$ ) is reversibly blocked with DHSM. $e$, The amplitude of the current suppressed by DHSM after elastase treatment is correlated $(r=0.95)$ with the receptor current before drug application. This indicates that the tonic current flows through permanently opened transducer channels after loss of tip links.

was partially $(50-70 \%)$ blocked by $250 \mu \mathrm{M}$ suramin without affecting mechanoelectrical transduction. The large difference between the amplitudes of the currents flowing through $\mathrm{P}_{2 \mathrm{X}}$ receptors and transducer channels is additional evidence that the sustained current after elastase treatment is not attributable to activation of $P_{2 X}$ receptors. That suramin still blocks the purinergic channels after elastase treatment was not tested in these experiments.

\section{Abolition of transduction by BAPTA}

Because lowering the extracellular $\mathrm{Ca}^{2+}$ concentration to sufficiently low levels $(<1 \mu \mathrm{M})$ has been shown to abolish transduction and destroy the tip links (Assad et al., 1991), the effects of BAPTA, a potent $\mathrm{Ca}^{2+}$ chelator, on the receptor current were investigated ( $n=8$ cells). Application of 5 mM BAPTA immediately and irreversibly abolished mechanoelectrical transduction (Fig. 4). Similar to the effect of elastase, a sustained inward current resulted from BAPTA application, which was maintained after mechanical stimulation was terminated. This finding suggests that the loss of mechanoelectrical transduction caused by the destruction of tip links by BAPTA leads to opening of the transducer channels. In analogy to the elastase experiments, the application of DHSM (100 $\mu \mathrm{M} ; n=8)$ after BAPTA treatment led to a total and reversible block of the tonic inward current (Fig. $5 a$ ), again indicating that the transducer channels were in an open state after BAPTA treatment. Two other known transducer-
Driving voltage $(8 \mathrm{~Hz})$
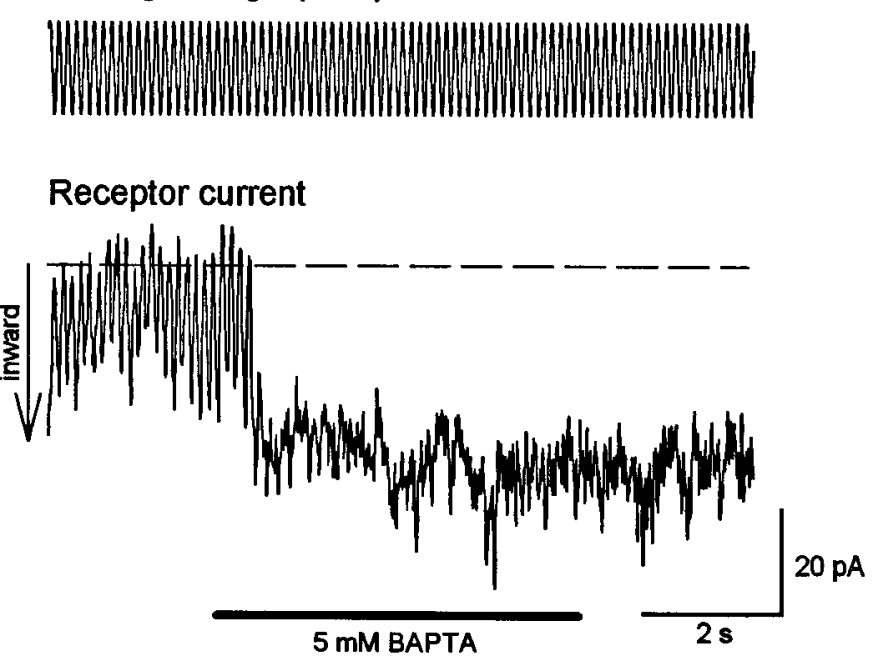

Figure 4. Effect of a reduction of extracellular $\mathrm{Ca}^{2+}$ on mechanoelectrical transduction. Application of $5 \mathrm{~mm}$ BAPTA, to reduce the extracellular $\mathrm{Ca}^{2+}$ concentration, results in an immediate and irreversible loss of the receptor current together with a sustained inward current approximately equal in magnitude to the receptor current before treatment. 

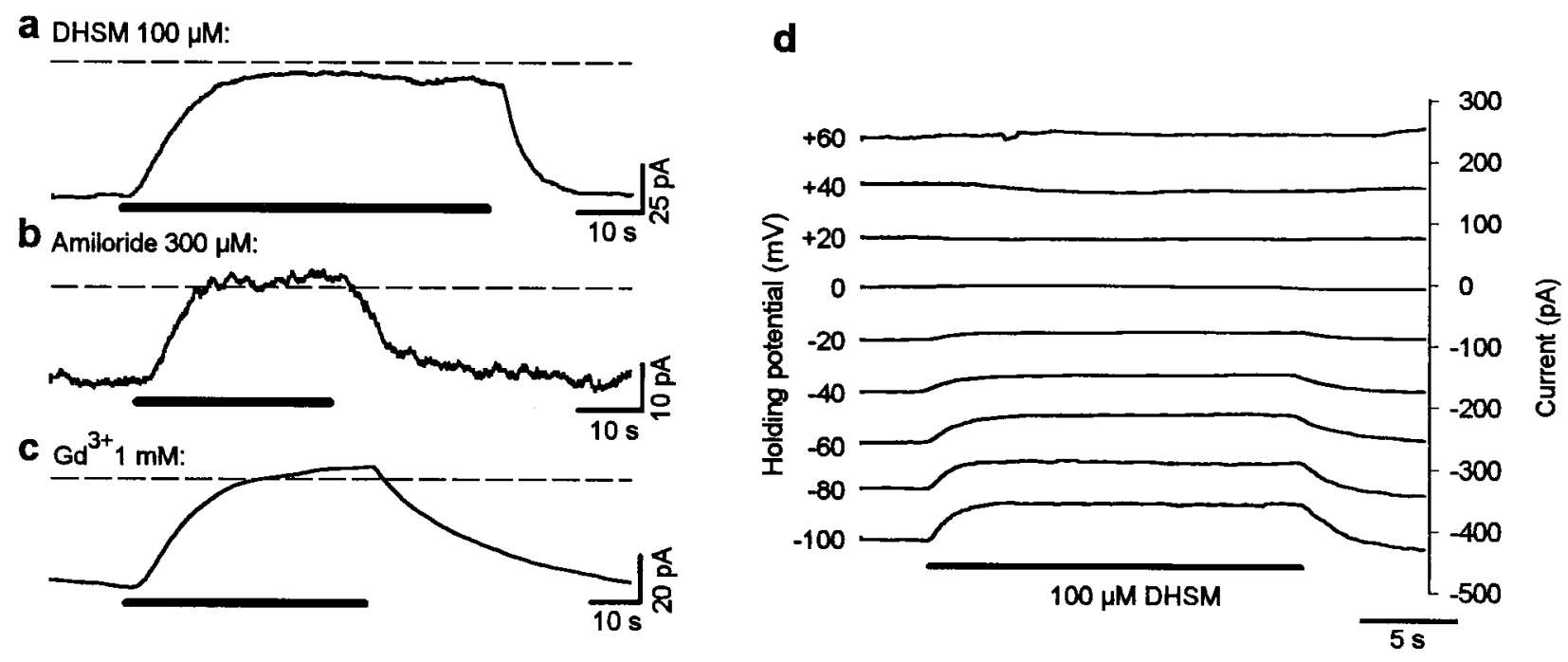

Figure 5. Pharmacological block of the sustained current induced by BAPTA treatment. $a-c$, Application of $100 \mu \mathrm{M}$ DHSM (a), $300 \mu \mathrm{M}$ amiloride (b), or $1 \mathrm{~mm}$ gadolinium ions $(c)$ leads to a total and reversible block of the tonic current induced by the treatment with 5 mM BAPTA. Horizontal bars indicate application of DHSM, amiloride, and $\mathrm{Gd}^{3+}$, respectively. $d$, DHSM blocks the tonic current at negative holding potentials in a voltage-dependent manner. These experiments indicate that the tonic current flows through permanently opened transduction channels after loss of tip links.

channel blockers, amiloride ( $300 \mu \mathrm{M} ; n=3)$ and gadolinium ions $(1 \mathrm{~mm} ; n=3)$, were also tested; both led to a total and reversible block of the sustained inward current after BAPTA treatment (Fig. 5b,c). Both DHSM (100 $\mu \mathrm{M} ; n=3$; Fig. $5 d)$ and gadolinium ions ( $1 \mathrm{~mm} ; n=3$; data not shown) blocked this sustained inward current at negative holding potentials in a voltage-dependent manner. The dependence of the amiloride block on voltage was not tested. For these experiments, $\mathrm{CsCl}$ was added to the internal solution to block most of the basolateral $\mathrm{K}^{+}$channels. Again, these results strongly suggest that the tonic current flows through transduction channels.

\section{DC shift in response to DHSM application}

The experiments presented above provide evidence for the opening of transducer channels after pharmacologically induced loss of tip links. Accordingly, channels could also open after mechanical disruption of tip links, as might occur because of the mechanical isolation procedure. In this context it is important that in response to DHSM application, approximately one-third of the cells not only showed a block of the $8 \mathrm{~Hz}$ receptor current but showed a DC shift in the inhibitory direction (Fig. 6b,c, arrows). The amplitude of this DC shift varied in different cells from hardly detectable values (Fig. 6a) to amplitudes larger than the receptor current (Fig. 6c). The size of the DC shift was not correlated with the amplitude of the receptor current. This kind of DC shift was also observed during application of amiloride (300 $\mu \mathrm{M}$; data not shown). A similar experiment with gadolinium ions was not conducted. Together with the finding that DHSM only blocks mechanoelectrical transducer channels in our experimental configuration, these DC shifts provide additional evidence of permanently opened transducer channels that do not respond to mechanical stimulation but that can be still blocked pharmacologically. The different amplitude of the DC shift for different cells may reflect different degrees of hair-bundle damage during the isolation procedure.

\section{Effect of elastase and BAPTA on hair-bundle morphology}

Stereociliary bundles were examined electron microscopically to establish that the concentrations of elastase and BAPTA specif- ically caused destruction of the tip links. In addition, the proportion of tip links that might have been damaged by the isolation procedure was investigated. Drugs were applied before glutaraldehyde fixation.

Qualitative morphological assessment of single cells (Fig. 7A) and of small clumps of cells in the control solution (HBSS alone) showed that many hair bundles were intact and that tip links were present (Fig. 7B). By contrast, after treatment of isolated cells with either $20 \mathrm{U} / \mathrm{ml}$ elastase (Fig. $7 C$ ) or 5 mM BAPTA (Fig. 7D), tip links were almost completely absent.

The degree of tip-link survival in each of these different treatments was quantified by counting the number of possible tip-link sites in the hair bundles of a random sample of cells and then by assessing the condition of the tip link at each site (Table 1). These counts showed that in controls, $30 \%$ of visible sites had intact tip links, whereas broken links and remnants were visible in a further 20 and $7 \%$, respectively. After BAPTA treatment for $10 \mathrm{sec}, 8 \%$ of links were still intact, and the numbers of broken links $(0.7 \%)$ and remnants $(3 \%)$ were reduced, although not proportional to the degree of tip-link loss. After longer BAPTA treatment (10 min), only $1.4 \%$ of links were intact, whereas more remnants were present $(6.5 \%)$. After elastase treatment, the number of intact links was reduced to $2.5 \%$, and neither remnants nor broken links were detected. However, side links appeared to be present after both elastase and BAPTA treatment. There was no morphological evidence of other effects on the hair bundle.

\section{DISCUSSION}

\section{Hair-bundle morphology after mechanical isolation}

The morphological observations with scanning electron microscopy demonstrate that at least $30 \%$ of tip links survive the isolation procedure. They also show that the concentrations of elastase and BAPTA chosen for the electrophysiological investigations result in almost complete loss of tip links. Although other isolated cells appeared to have damaged stereocilia, only cells with intact hair bundles determined by light microscopy were chosen for the electrophysiological experiments. The percentage of intact tip links found in the control group of isolated OHCs after preparation for scanning electron microscopy (30\%) is only 


\section{Driving voltage $(8 \mathrm{~Hz})$

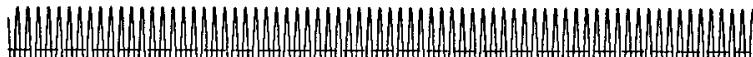 -}

\section{Receptor current}

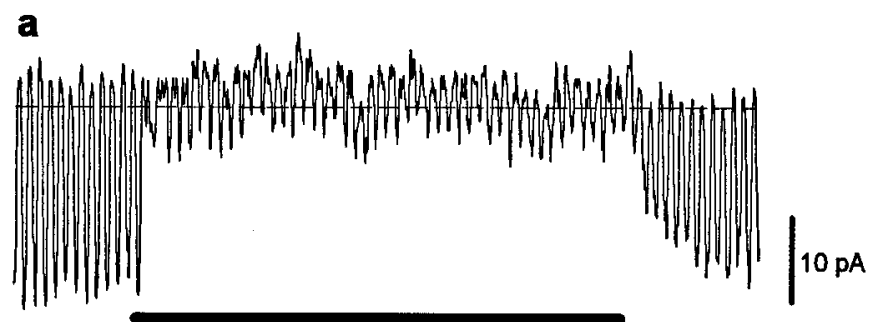

DHSM $100 \mu \mathrm{M}$
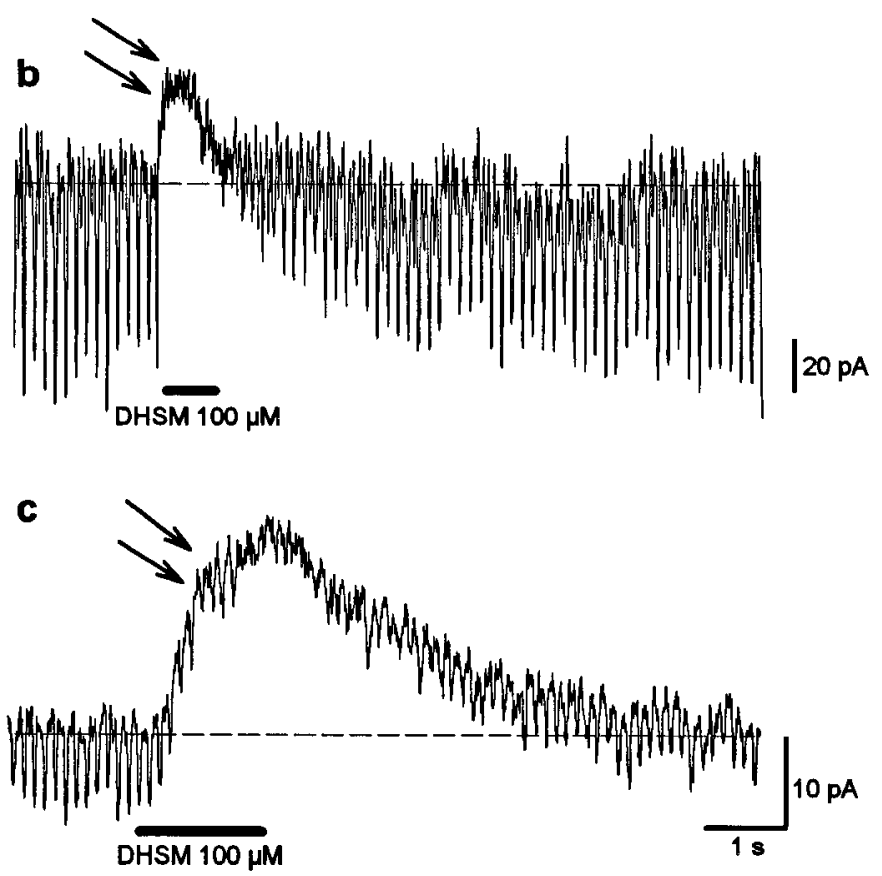

Figure 6. In addition to blocking mechanotransduction, dihydrostreptomycin leads to a DC shift in the inhibitory direction in some cells. The amplitude of the DC shift varies from hardly detectable $(a)$ to larger $(b)$ values that could be much greater than the receptor current $(c)$. This DC shift indicates a block of opened, mechanically insensitive ion channels.

slightly lower than that for bullfrog saccular hair cells $(39 \%)$ in the intact epithelium reported by Assad et al. (1991). However, because it is not possible to determine whether the broken links or remnants observed are the result of the isolation procedure or the shrinkage that occurs during the subsequent preparation for scanning electron microscopy, the data suggest that the average proportion of links surviving after isolation lies between 30 and $57 \%$. Thus, the number of intact tip links was more than an order of magnitude higher in the control cells than in the elastase- or BAPTA-treated cells. In this context, it is important to note that the hair cells for both the electrophysiological and the morphological investigations were isolated using identical procedures performed by the same person (J.M.).

\section{Receptor currents of isolated OHCs}

Isolated OHCs from the adult guinea pig cochlea are reported to be metabolically viable for at least $2 \mathrm{hr}$, as ascertained by mea-
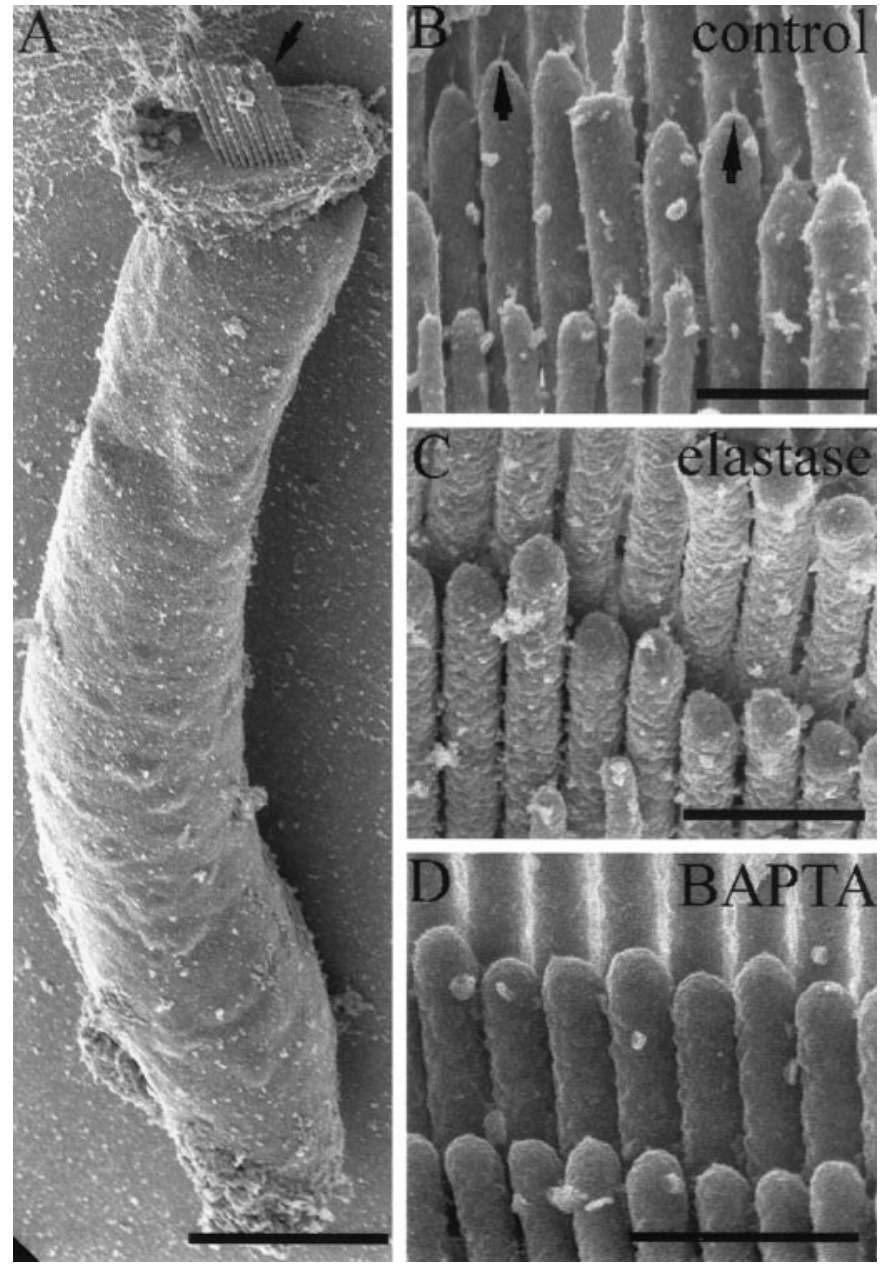

Figure 7. Effect of elastase and BAPTA on hair-bundle morphology. A, An example of a single hair cell after the isolation procedure. Note the intact hair bundle at the apex of the cell (arrow). Scale bar, $10 \mu \mathrm{m}$. B, Detail of a stereociliary bundle from an isolated hair cell after incubation in HBSS alone. Note the presence of tip links on many of the stereocilia (arrows). C, A stereociliary bundle after elastase treatment $(20 \mathrm{U} / \mathrm{ml})$. Note the complete absence of tip links. $D$, A stereociliary bundle after 10 min of BAPTA treatment (5 mM). Tip links are completely absent. Scale bars: $B-D, 750 \mathrm{~nm}$.

suring the intracellular ATP concentration (Puschner and Schacht, 1997). Although many hair bundles seem to be morphologically intact after mechanical isolation (Fig. 7), the mechanically elicited receptor currents (10-112 pA; mean, 40 pA) appear to be small compared with other hair-cell systems; the amplitudes of receptor currents also show a wide range in different studies. For bullfrog, turtle, or neonatal mouse hair cells, receptor currents up to several hundred picoamperes have been reported (e.g., Corey and Hudspeth, 1983; Crawford et al., 1991; Kros et al., 1992; Rüsch et al., 1994), particularly when intact epithelia have been used. However, it must be remembered that the hair-bundle morphology is different in other systems. Whereas nonmammalian hair cells contain up to 300 stereocilia arranged in several rows (Hudspeth, 1989), stereocilia of adult OHCs are arranged only in two to three rows, and the total number is lower, decreasing from the base to the apical half of the cochlea and from the first to the third row of OHCs (Lim, 1986). Most of the cells used in this study for patch-clamp recordings originated from the apical part of the cochlea, where the number of stereocilia can be 
Table 1. Quantitative analysis of tip links after treatment with BAPTA or elastase

\begin{tabular}{|c|c|c|c|c|c|c|c|c|c|}
\hline \multirow[b]{2}{*}{ Treatment } & \multicolumn{4}{|c|}{ Proportions overall } & \multicolumn{5}{|c|}{ Proportions of visible sites } \\
\hline & $\begin{array}{l}\text { Possible } \\
\text { sites }\end{array}$ & $\begin{array}{l}\text { Obscured } \\
\text { sites }\end{array}$ & $\begin{array}{l}\text { Fused } \\
\text { sites }\end{array}$ & $\begin{array}{l}\text { Visible } \\
\text { sites }\end{array}$ & $\begin{array}{l}\text { Intact } \\
\text { tip links }\end{array}$ & $\begin{array}{l}\text { Absent } \\
\text { tip links }\end{array}$ & $\begin{array}{l}\text { Remnant } \\
\text { tip links }\end{array}$ & $\begin{array}{l}\text { Broken } \\
\text { tip links }\end{array}$ & $\begin{array}{l}\text { Uncertain } \\
\text { tip links }\end{array}$ \\
\hline Control & 433 & $64(15 \%)$ & $17(4 \%)$ & $352(81 \%)$ & $106(30 \%)$ & $118(34 \%)$ & $25(7 \%)$ & $71(20 \%)$ & $32(9 \%)$ \\
\hline BAPTA short & 514 & $42(8.2 \%)$ & $47(9.1 \%)$ & $425(83 \%)$ & $33(7.8 \%)$ & $352(83 \%)$ & $13(3.1 \%)$ & $3(0.7 \%)$ & $24(5.6 \%)$ \\
\hline BAPTA long & 437 & $24(5.5 \%)$ & $60(14 \%)$ & $353(81 \%)$ & $5(1.4 \%)$ & $316(90 \%)$ & $23(6.5 \%)$ & $0(0 \%)$ & $9(2.6 \%)$ \\
\hline Elastase & 160 & $15(9.4 \%)$ & $23(14 \%)$ & $122(76 \%)$ & $3(2.5 \%)$ & $114(93 \%)$ & $0(0 \%)$ & $0(0 \%)$ & $5(4.1 \%)$ \\
\hline
\end{tabular}

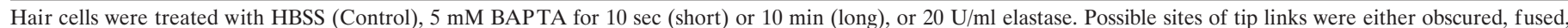

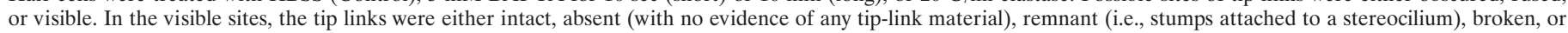

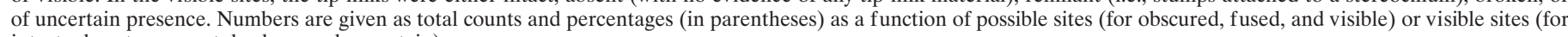
intact, absent, remnant, broken, and uncertain).

extremely small, as few as 20 (D. N. Furness, personal observation). The results from neonatal cultured mouse hair cells are also not directly comparable with those from OHCs from the adult guinea pig cochlea because they have a different morphology. Unlike adult hair cells, neonatal hair cells have a kinocilium and show a variety of additional links between stereocilia (Furness et al., 1989). Moreover, the stereocilia are much smaller and presumably stiffer, and there are several more rows in the hair bundle (Furness et al., 1989). Nevertheless, the transduction currents reported in our study are comparable with those reported for chick hair cells (<100 pA) (e.g., Kimitsuki and Ohmori, 1993; Kimitsuki et al., 1996; Zhao et al., 1996). Although not specifically investigated here, other studies from our laboratory have shown that the size of the saturated receptor potentials of adult, isolated hair cells (Preyer et al., 1996) is comparable with those of intracellular potentials in vivo. Taken together with the quantitative electron microscopical investigations reported here, we conclude that although the receptor currents are smaller than in other species, the isolated hair cells appear to possess between 30 and $60 \%$ of their normal complement of tip links and that the size of the currents are consistent with the number of stereocilia in the hair bundle.

\section{Block of mechanoelectrical transduction by dihydrostreptomycin}

Aminoglycoside antibiotics are known to reduce the receptor current of mechanoelectrical transduction channels in a dose- and voltage-dependent manner (Kroese et al., 1989; Denk et al., 1992; Kimitsuki and Ohmori, 1993). Because of its large molecular size $(>1 \mathrm{~nm})$ compared with the estimated diameter of the channel pore $(\sim 0.7 \mathrm{~nm})$, DHSM appears to block the pore physically (Kroese et al., 1989). In our experiments, the application of DHSM to a hair bundle statically deflected to close the channels also had no effect, strongly suggesting that DHSM blocks only the transduction channels. Thus, an effect of DHSM on the basolateral channels in these experiments can be safely excluded. Control experiments with the purinoreceptor antagonist suramin showed that the reduced current was not caused by the action of DHSM on the $\mathrm{P}_{2 \mathrm{X}}$ receptors, prevalent in hair-cell stereocilia (Mockett et al., 1994). Therefore, DHSM served as a potent means of specifically blocking mechanoelectrical transduction channels to study the action of the proteolytic enzyme elastase as well as BAPTA on the transduction apparatus.

\section{Loss of mechanoelectrical transduction by elastase and BAPTA}

The enzyme elastase is known to destroy tip links, as shown electron microscopically for frog vestibular hair cells (Takumida et al., 1993) or fixed hair cells from the guinea pig cochlea (Osborne and Comis, 1990). These authors reported an almost complete absence of tip links after elastase incubation for $10 \mathrm{~min}$ with the same concentration used in this study $(20 \mathrm{U} / \mathrm{ml})$. Side links were less damaged (Osborne and Comis, 1990). Comparable results were obtained in this study using unfixed isolated OHCs. Elastase produced almost total loss of tip links without leaving any remnant or broken links. This is consistent with enzymatic degradation and implies a direct effect by elastase on the link itself or on both of its anchoring structures. However, it cannot be concluded that the tip links consist of elastin; (1) elastase is known to digest other extracellular matrix proteins (Gronski et al., 1997), and (2) antibodies raised against elastin fail to label any part of the organ of Corti (Katori et al., 1996).

Preyer et al. (1995) showed that elastase led to an irreversible loss of the receptor potential of isolated OHCs after a few seconds of application. They interpreted their results as a verification of the tip-link hypothesis. Indeed, from their experiments it seems clear that tip links are essential elements for the transduction apparatus of cochlear hair cells. The suggested gatingspring model for mechanoelectrical transduction assumes the tip link-the gating spring-to be connected directly to the channel protein (Gillespie, 1995). If true, then destruction of tip links should lead to closure of the transducer channels because of the absence of an elastic restoring force. The closure of the mechanoelectrical channels should be observed as a reduction of current flow into the cell, comparable with the situation during block of the transducer channels with DHSM. The experiments presented here have clearly shown that the cells are no longer sensitive to mechanical stimulation after elastase treatment. But instead of a loss of current, a permanent inward current was observed that could be totally and reversibly blocked with DHSM. This effect can be explained by the transduction channels remaining in the open state after loss of tip links. This result is not consistent with the tip-link hypothesis.

Low extracellular calcium levels $(<1 \mu \mathrm{M})$, achieved by application of $\mathrm{Ca}^{2+}$ chelators such as BAPTA, are known to lead to destruction of tip links and to loss of mechanoelectrical transduction (Assad et al., 1991; Crawford et al., 1991). BAPTA treatment had a rapid effect, the number of intact tip links being substantially reduced within $10 \mathrm{sec}$ (8\% remaining). However, a $10 \mathrm{~min}$ treatment with BAPTA resulted in an almost total loss of tip links (1.4\% remaining), whereas the proportion that remained as remnants was greater $(6.5 \%)$. This suggests that as well as destroying most links, BAPTA may weaken the remaining links, making them more susceptible to damage during preparation for electron microscopy. This is consistent with a chemical alteration of the 
links during BAPTA treatment and accords with the suggestion that the link consists of two components held together at a $\mathrm{Ca}^{2+}$-dependent site that becomes uncoupled after reduction of the $\mathrm{Ca}^{2+}$ concentration (Assad et al., 1991). This appears to differ from the effects of elastase in that the former removes all evidence of the link, whereas the latter occasionally leaves some remnants at the anchoring points (Table 1).

The BAPTA experiments presented here resulted in effects similar to that of the elastase experiments, again suggesting that the transduction channels of treated hair bundles were in an open configuration. That both enzymatic and nonenzymatic means of destroying tip links caused similar effects on transduction provides strong evidence that transducer channels open after tip-link loss, without being damaged. Assad et al. (1991) also reported an increase of total membrane current after treatment with BAPTA. They suggested that a shift in the activation of basolaterally situated voltage-dependent $\mathrm{Ca}^{2+}$ channels caused the current increase. However, two lines of evidence are provided here for the increased current being attributable to permanently opened transduction channels; (1) the tonic current resulting from BAPTA treatment in our experiments had about the same magnitude as the receptor current, and (2) the tonic current could be totally and reversibly blocked by DHSM, amiloride, and gadolinium ions.

Experiments with turtle hair cells have also shown a loss of mechanoelectrical transduction after exposure to low calcium (Crawford et al., 1991). The authors observed a strong inward current immediately after treatment with low-calcium saline. This strong inward current is reported to return to near the control level. However, it must be pointed out that in contrast to our procedure, the experiments by Crawford et al. (1991) were performed by bathing whole cells in saline of different calcium concentrations. Therefore, an effect on the basolateral membrane or the hair bundle cannot be excluded in their experiments. Control experiments with a fluorescent dye (Lucifer yellow) suggested that in the present electrophysiological experiments, diff usion of the applied chemicals was localized to the stereocilia bundle (Preyer et al., 1995). This could explain the difference between the present results and those of Crawford et al. (1991). It should be noted that when cells are exposed to low-calcium saline, fusion of adjacent stereocilia may occur (Hackney et al., 1997). In the present study, application of low-calcium saline to the hair bundles also produced a degree of fusion, but the majority of stereocilia remained unfused, so that this cannot fully explain the effects on transduction observed here.

\section{Implications for the localization of the transducer channels}

The precise location of the transducer channels remains unknown (Gillespie, 1995; Hackney and Furness, 1995). It seems relatively clear that one or two functional channels are located in the upper region of each stereocilium (Jaramillo and Hudspeth, 1991; Denk et al., 1995; Lumpkin and Hudspeth, 1995), a finding that was consistent with the hypothesis that the transducer channels are directly gated by the tip links. However, the opening of the transducer channels after loss of tip links reported here suggests an indirect interaction between the tip links and the channels.

\section{REFERENCES}

Ashmore JF, Ohmori H (1990) Control of intracellular calcium by ATP in isolated outer hair cells of the guinea-pig cochlea. J Physiol (Lond) 428:109-131.
Assad JA, Shepherd GMG, Corey DP (1991) Tip-link integrity and mechanical transduction in vertebrate hair cells. Neuron 7:985-994.

Corey DP, Hudspeth AJ (1979) Response latency of vertebrate hair cells. Biophys J 26:499-506.

Corey DP, Hudspeth AJ (1983) Kinetics of the receptor current in bullfrog saccular hair cells. J Neurosci 3:962-976.

Crawford AC, Evans MG, Fettiplace R (1991) The actions of calcium on the mechano-electrical transducer currents of turtle hair cells. J Physiol (Lond) 434:369-398.

Denk W, Keolian RM, Webb WW (1992) Mechanical response of frog saccular hair bundles to the aminoglycoside block of mechanoelectrical transduction. J Neurophysiol 68:927-932.

Denk W, Holt JR, Shepherd MG, Corey DP (1995) Calcium imaging of single stereocilia in hair cells: localization of transduction channels at both ends of tip links. Neuron 15:1311-1321.

Furness DN, Richardson GP, Russell IJ (1989) Stereociliary bundle morphology in organotypic cultures of the mouse cochlea. Hear Res 38:95-110.

Gillespie PG (1995) Molecular machinery of auditory and vestibular transduction. Curr Opin Neurobiol 5:449-455.

Gronski Jr TJ, Martin RL, Kobayashi DK, Walsh BC, Holman MC, Huber M, Van Wart HE, Shapiro SD (1997) Hydrolysis of a broad spectrum of extracellular matrix proteins by human macrophage elastase. J Biol Chem 272:12189-12194.

Hackney CM, Furness DN (1995) Mechanotransduction in vertebrate hair cells: structure and function of the stereociliary bundle. Am J Physiol 268:C1-C13.

Hackney CM, Furness DN, Mahendrasingam S, Macnamara M (1997) Ultrastructural and immunocytochemical investigations of the mechanotransducing apparatus of vertebrate hair cells. Proc Sendai Ear Symp 7:83-86.

Hamill OP, Marty A, Neher A, Sakmann B, Sigworth FJ (1981) Improved patch-clamp technique for high-resolution current recording from cells and cell-free membrane patches. Pflügers Arch 391:85-100.

Howard J, Roberts WM, Hudspeth AJ (1988) Mechanoelectrical transduction by hair cells. Annu Rev Biophys Biophys Chem 17:99-124.

Hudspeth AJ (1982) Extracellular current flow and the site of transduction by vertebrate hair cells. J Neurosci 2:1-10.

Hudspeth AJ (1989) How the ear's works work. Nature 341:397-404.

Hudspeth AJ, Jacobs R (1979) Stereocilia mediate transduction in vertebrate hair cells. Proc Natl Acad Sci USA 76:1506-1509.

Jaramillo F, Hudspeth AJ (1991) Localization of the hair cell's transduction channels at the hair bundle's top by iontophoretic application of a channel blocker. Neuron 7:409-420.

Katori Y, Hackney CM, Furness DN (1996) Immunoreactivity of sensory hair bundles of the guinea-pig cochlea to antibodies against elastin and keratan sulphate. Cell Tissue Res 284:473-479.

Kimitsuki T, Ohmori H (1993) Dihydrostreptomycin modifies adaptation and blocks the mechano-electric transducer in chick cochlear hair cells. Brain Res 624:143-150.

Kimitsuki T, Nakagawa T, Hisashi K, Komune S, Komiyama S (1996) Gadolinium blocks mechano-electric transducer current in chick cochlear hair cells. Hear Res 101:75-80.

Kroese ABA, Das A, Hudspeth AJ (1989) Blockage of the transduction channels of hair cells in the bullfrog's sacculus by aminoglycoside antibiotics. Hear Res 37:203-218.

Kros CJ, Rüsch A, Richardson GP (1992) Mechano-electrical transducer currents in hair cells of the cultured neonatal mouse cochlea. Proc R Soc Lond [Biol] 249:185-193.

Lim DJ (1986) Functional structure of the organ of Corti: a review. Hear Res 22:117-146.

Lin X, Hume RI, Nuttall AL (1993) Voltage-dependent block by neomycin of the ATP-induced whole cell current of guinea-pig outer hair cells. J Neurophysiol 70:1593-1605.

Lumpkin EA, Hudspeth AJ (1995) Detection of $\mathrm{Ca}^{2+}$ entry through mechanosensitive channels localizes the site of mechanoelectrical transduction in hair cells. Proc Natl Acad Sci USA 92:10297-10301.

Meyer J, Preyer S, Zenner H-P, Gummer AW (1997) The effect of static hair-bundle displacement on the mechanoelectric transduction in isolated cochlear hair cells. In: Diversity in auditory mechanics (Lewis ER, Long GR, Lyon RF, Narins PM, Steele CR, Hecht-Poinar E, eds), pp 538-541. London: World Scientific.

Mockett BG, Housley GD, Thorne PR (1994) Fluorescence imaging of extracellular purinergic receptor sites and putative ecto-ATPase sites on isolated cochlear hair cells. J Neurosci 14:6992-7007. 
Nakagawa T, Akaike N, Kimitsuki T, Komune S, Arima T (1990) ATPinduced current in isolated outer hair cells of guinea pig cochlea. J Neurophysiol 63:1068-1074.

Osborne MP, Comis SD (1990) Action of elastase, collagenase and other enzymes upon linkages between stereocilia in the guinea-pig cochlea. Acta Otolaryngol 110:37-45.

Pickles JO, Comis SD, Osborne MP (1984) Cross-links between stereocilia in the guinea-pig organ of Corti and their possible relation to sensory transduction. Hear Res 15:103-112.

Preyer S, Hemmert W, Zenner HP, Gummer AW (1995) Abolition of the receptor potential response of isolated mammalian outer hair cells by hair-bundle treatment with elastase: a test of the tip-link hypothesis. Hear Res 89:187-193.

Preyer S, Renz S, Hemmert W, Zenner HP, Gummer AW (1996) Receptor potential of outer hair cells isolated from base to apex of the adult guinea-pig cochlea: implications for cochlear tuning mechanisms. Aud Neurosci 2:145-157.
Puschner B, Schacht J (1997) Energy metabolism in cochlear outer hair cells in vitro. Hear Res 114:102-106.

Rüsch A, Kros CJ, Richardson GP (1994) Block by amiloride and its derivatives of mechano-electrical transduction in outer hair cells of mouse cochlear cultures. J Physiol (Lond) 474:75-86.

Saunders JC, Szymko YM (1989) The design, calibration, and use of a water microjet for stimulating hair cell sensory hair bundles. J Acoust Soc Am 86:1797-1804.

Shotwell SL, Jacobs R, Hudspeth AJ (1981) Directional sensitivity of individual vertebrate hair cells to controlled deflection of hair bundles. Ann NY Acad Sci 374:1-10.

Takumida M, Harada Y, Kanemi Y (1993) Influence of elastase and hyaluronidase on the ciliary interconnecting systems in frog vestibular sensory cells. ORL J Otorhinolaryngol Relat Spec 55:77-83.

Zhao YD, Yamoah EN, Gillespie PG (1996) Regeneration of broken tip links and restoration of mechanical transduction in hair cells. Proc Natl Acad Sci USA 94:15469-15474. 